\title{
Oral anticoagulation in paediatric patients: dose requirements and complications
}

\author{
R C Tait, E J Ladusans, M El-Metaal, R G Patel, A M Will
}

Royal Manchester Children's Hospital, Pendlebury, Manchester:

Department of Haematology

R C Tait A $M$ Will

Department of Cardiology E J Ladusans R G Patel

Department of Haematology, Hope Hospital, Salford M El-Metaal

Correspondence to: Correspondence to: Haematology, Royal Maematology, Royal Manchester Children's Hospital, Pendlebury,

Accepted 15 November 1995

\begin{abstract}
The lack of oral anticoagulant guidelines specific to paediatric practice has led to the adoption of adult regimens, often without scientific evidence of efficacy or safety. A two year prospective study of anticoagulant control was carried out in 45 children aged 9 months to 18 years, the majority of whom were receiving primary prophylactic anticoagulation. The main indication was congenital heart disease, either with $(n=8)$ or without $(n=34)$ mechanical valve prosthesis. During a follow up period of $\mathbf{6 0 2}$ patient months the average interval between visits was three weeks. Target international normalised ratios (INRs) were achieved on $62 \%$ and $39 \%$ of visits for children with low target INR (2.0-3.0) and high target INR $(3 \cdot 0-4 \cdot 0)$ respectively. However warfarin dose was altered on only $22 \%$ of visits. Warfarin doses required to achieve a stable INR of $2 \cdot 0-3.0$ in 33 children were strongly correlated with weight [dose $(\mathrm{mg} / \mathrm{d})=0.07 \times$ weight $(\mathrm{kg})+0.54]$ but independently influenced by age. No thrombotic complications were recorded, and haemorrhagic events were infrequent ( $2 \cdot 1 \%$ of visits) and, with one exception, minor. Safe outpatient oral anticoagulation is feasible in children, whose warfarin requirements appear moderately predictable and whose control is no more erratic than that of adults.

(Arch Dis Child 1996; 74: 228-231)
\end{abstract}

Keywords: oral anticoagulation, anticoagulant control, children.

that a weekly paediatric anticoagulant clinic was established. This prompted a two year prospective study of all children referred, to establish the primary indications for anticoagulants and the degree and duration of anticoagulation required, and to assess the quality and safety of monitoring provided by the clinic.

\section{Methods}

PATIENT RECRUITMENT

From October 1992 to October 1994, 45 patients attended the anticoagulant clinic for outpatient monitoring. All relevant clinical details were established at referral. At each visit, we recorded clinical details, changes in medication, INR result, and anticoagulant (warfarin) dose. Children's weights were noted at times of apparent stable anticoagulation when INR results remained within target, without change in warfarin dose, over a period of at least four weeks. We recorded details of all haemorrhagic or thrombotic events occurring at, or away from, the parent centre.

As a comparison for warfarin maintenance dose requirements, 17 adult patients attending an adult anticoagulant clinic were monitored with the same capillary INR reagent. All were receiving primary prophylactic warfarin treatment and stably maintained with INRs of $2 \cdot 0-3 \cdot 0$. Their ages ranged from 51 to 81 years (median 64 years) and median daily warfarin requirement was $3.5 \mathrm{mg}(0.047 \mathrm{mg} / \mathrm{kg})$.

\section{WARFARIN CONTROL}

All patients were monitored by INR results determined by a manual capillary whole blood method using commercial reagents (Nycomed). Warfarin was prescribed by any of three medical personnel who titrated doses to each patient's INR target range. However, unlike computerised dosing regimens, there was no strict protocol, since isolated INR results just outside the target range did not always trigger a dose alteration. ably reflected the small number of indications for either short or long term anticoagulation in children. Thus there have been no adequate trials to establish optimal anticoagulant guidelines, and therapeutic protocols appear to have been extrapolated from recommendations for adults with similar indications. ${ }^{1-3}$ Nevertheless there remains concern and debate over initiation and maintenance dose requirements, optimal target international normalised ratio (INR) ranges, as well as the potential for variable compliance and erratic control in particularly young patients. ${ }^{124}$

During 1992 the number of children referred to our institution for outpatient monitoring of oral anticoagulants increased to such an extent
The relations between dose requirement and weight or age were examined by simple regression analysis. The relation between dose and surface area was not examined because of concern over reliability of surface area derivation in particularly young children. Statistical comparison of dose requirements, adjusted for weight, between different age ranges was limited by small numbers, particularly in the youngest and oldest groups. However, calculation of median dose requirements, and the

\section{STATISTICAL ANALYSIS}


Table 1 Target INR ranges and indications for oral anticoagulation

\begin{tabular}{|c|c|c|}
\hline Target INR & Indication & No \\
\hline \multirow[t]{4}{*}{$2 \cdot 0-3 \cdot 0$} & $\begin{array}{l}\text { Primary prophylaxis } \\
\text { Fontan surgery }\end{array}$ & 32 \\
\hline & Secondary prophylaxis & \\
\hline & Deep vein thrombosis & 1 \\
\hline & $\begin{array}{l}\text { Bacterial endocarditis +embolus } \\
\text { Fontan surgery +embolus }\end{array}$ & 1 \\
\hline \multirow{4}{*}{$3 \cdot 0-4 \cdot 0$} & Primary prophylaxis & \\
\hline & Mechanical prosthetic valve ${ }^{b}$ & 8 \\
\hline & Secondary prophylaxis & \\
\hline & Bacterial endocarditis + embolus & 1 \\
\hline
\end{tabular}

aThree patients initially requested to have INR maintained in range $2 \cdot 5-3 \cdot 5$.

'Two patients with INR maintained in range 3.0-4.5 and one other had target INR range reduced to $2 \cdot 0-3 \cdot 0$ after recurrent epistaxis.

INR, international normalised ratio.

interquartile ranges, gave some indication of the independent importance of age.

\section{Results}

Over the two year period of study 45 children were monitored for a cumulative total of 602 patient months (approximately 50 patient years). There were 18 girls and 27 boys, aged from 9 months to 18 years (median 6 years). The duration of anticoagulation before entry into the study ranged from two weeks to seven years, approximately half $(n=22)$ entering the study within three months of starting warfarin. The remainder were already well established when study monitoring began (14 children on warfarin for 3-12 months; nine on warfarin for more than one year).

The indications for anticoagulation and target INR ranges for these children are summarised in table 1 . The majority were receiving primary prophylactic anticoagulation, only five having had a previous thrombotic or embolic event. The largest single group consisted of 34 children who had undergone a Fontan procedure. In all these children, as well as in those with mechanical prosthetic heart valves, the intended duration of anticoagulation was longer than one year.

There were two target INR categories: high INR range, $3 \cdot 0-4 \cdot 0$ (or in two children, $3 \cdot 0-4 \cdot 5$ ), for patients with mechanical prosthetic heart valves; and low INR range, $2 \cdot 0-3 \cdot 0$, for other indications. During the two

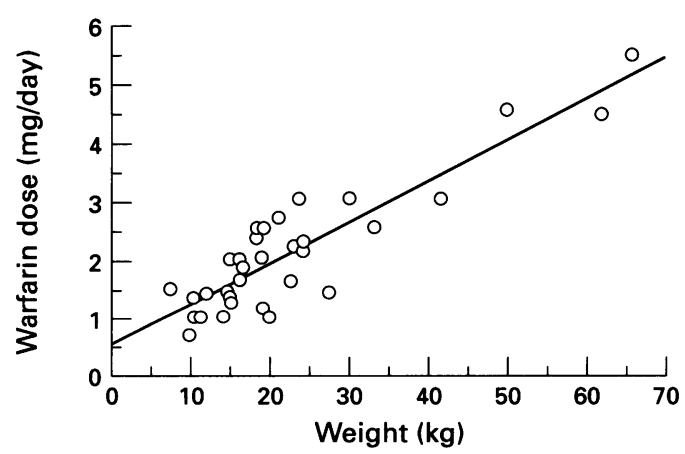

Relation between weight and warfarin dose required to maintain an international normalised ratio (INR) of $2 \cdot 0-3 \cdot 0$. Warfarin requirements for 33 children, taking no interfering drugs, at time of stable INR in the range $2 \cdot 0-3 \cdot 0$ showed a strong correlation with child's weight $(r=0.90)$. Regression analysis defined the relation: warfarin dose $(\mathrm{mg} / \mathrm{d})=0.07 \times$ weight $(\mathrm{kg})+0.54$. years there were 825 clinic visits with an average of three weeks between visits, this being similar for both low and high INR groups. In the low INR group, results were within target on $62 \%$ visits, below target on $24 \%$, and over target on $14 \%$. On only $3 \%$ of visits was the INR greater than $4 \cdot 5$. However, in the high INR group control was less good, with INR being within target on only $39 \%$ of visits and below target on $52 \%$ of visits. Despite the apparently poorer control in this group, dose alterations were made on only $22 \%$ of visits (on average every three months) - the same frequency as in the low INR group.

The reasons for out of target INR results was rarely identifiable. Only $15 \%$ of such episodes were putatively related to incomplete compliance, concurrent infection, use of antibiotics, or changes in regular medication. Indeed $33 \%$ of children were on no regular medication other than warfarin. The remainder were taking combinations of drugs (frequently diuretics, digoxin, or an angiotensin converting enzyme inhibitor), the majority of which are not regarded as interfering with coumarin effect. ${ }^{35}$ Notably, however, four children who were started on amiodarone required a warfarin dose reduction of $30-50 \%$.

Adverse events attributable to poor anticoagulant control were infrequent, with no thrombotic episodes observed. Two patients died during the study period, both from underlying cardiac disease. Minor bruising or epistaxis was recorded at $2 \cdot 1 \%$ of all visits $(1 \cdot 4 \%$ in low $\mathrm{INR}$ group and $4.8 \%$ in high INR group). However, in only one patient, with recurrent epistaxis which did not respond to cautery, was the target INR reduced from the high to the low range. One patient, with a poor attendance record at the clinic, suffered a non-fatal subdural haematoma when INR was $>10$. Another teenage girl had an INR $>10$ after taking an intentional warfarin overdose. This was treated without haemostatic complications.

Warfarin dose requirements $(\mathrm{mg} / \mathrm{d})$ were analysed for the group of 33 children in the low INR group who were not receiving any potentially interfering concurrent medication. There were strong positive correlations with both age $(r=0 \cdot 81)$ and weight $(r=0 \cdot 90)$. Regression analysis (figure) revealed the relation:

warfarin dose $(\mathrm{mg} / \mathrm{d})=0.07 \times$ weight $(\mathrm{kg})+0.54$

There were no apparent differences in warfarin requirements between boys and girls.

Table 2 Maintenance dose warfarin requirements in different patient categories

\begin{tabular}{llrll}
\hline & $\begin{array}{l}\text { Age } \\
\text { Target INR }\end{array}$ & & \multicolumn{2}{c}{ Maintenance dose $(\mathrm{mg} / \mathrm{kg} / \mathrm{d})$} \\
\cline { 5 - 6 } & (years) & No & Median & (interquartile range) \\
\hline $2 \cdot 0-3 \cdot 0$ & $<2$ & 3 & $0 \cdot 136$ & $(0 \cdot 109-0 \cdot 186)$ \\
& $2-5$ & 15 & $0 \cdot 107$ & $(0 \cdot 089-0 \cdot 127)$ \\
& $6-10$ & 11 & $0 \cdot 095$ & $(0 \cdot 074-0 \cdot 102)$ \\
$3 \cdot 0-4 \cdot 0$ & $11-18$ & 4 & $0 \cdot 077$ & $(0 \cdot 072-0 \cdot 086)$ \\
$2 \cdot 0-3.0$ & $3-14$ & 8 & $0 \cdot 124$ & $(0 \cdot 096-0 \cdot 172)$ \\
& $51-81$ & 17 & 0.047 & $(0.032-0 \cdot 060)$ \\
\hline
\end{tabular}

Only patients in stable maintenance phase, and taking no drugs known to significantly alter warfarin requirements, were included in analysis. All adult patients having warfarin as primary prophylaxis.

primary prophylaxis. 
However, the independent effect of age was evident when dose requirements adjusted for weight $(\mathrm{mg} / \mathrm{kg} / \mathrm{d})$ were compared for different age ranges (table 2). Although the numbers of children in the youngest and oldest age groups are small, there appears to be a clear inverse relation between warfarin dose and age. Even the oldest children appear to require more warfarin per $\mathrm{kg}$ than a control group of stably anticoagulated adults (age range 51-81 years).

\section{Discussion}

Over the last 20 years little has been published on the use of anticoagulants in children. Recent guidelines on oral anticoagulation, ${ }^{3}$ prepared on behalf of the British Committee for Standards in Haematology, give no specific advice for dosing or monitoring in children other than commenting that the dose schedule should be reduced in patients of less than average body weight. A recent survey of 407 haematologists and 22 United Kingdom centres dealing with paediatric cardiology or cardiothoracic surgery showed that most centres had little experience in this field. ${ }^{1}$ This report revealed that the majority of children receiving oral anticoagulants had prosthetic cardiac valves $(74 \%)$ and that target INR ranges were similar to those used in adults. However, there is little scientific evidence that such empirical regimes provide the optimal balance between efficacy and safety in children.

Before 1992, our own experience of oral anticoagulants in children was limited to a few patients with prosthetic valves and the rare case of venous thrombosis. However, over the last few years we have been asked to monitor an increasing number of children taking warfarin for congenital heart disease without prosthetic valves. The majority had undergone Fontan procedures which can be used to treat a variety of complex congenital heart anomalies (particularly tricuspid atresia), where benefit may be gained by establishing a shunt from the right atrium to the pulmonary artery. Unfortunately the subsequent rise in right atrial pressures can lead to complications and an apparently high rate of thromboembolism, possibly related to reduced levels of protein C. ${ }^{6}$ Hence most children in our region having such operations receive primary prophylactic anticoagulation. Interestingly a similar study to our own, carried out in Canada and reported in 1994 by Andrew et $a l,{ }^{4}$ included 67 children with congenital heart disease $-73 \%$ having no mechanical valve prostheses. It therefore seems likely that such patients will become increasingly common in paediatric anticoagulant clinics. The Canadian findings are broadly similar to our own but there are important differences which probably reflect the composition of the patient populations.

Most of our cohort was started on warfarin outside our centre and therefore we are not able to determine the optimal loading regime. Previous reports describe a wide range of loading doses, from $0 \cdot 1-1 \cdot 0 \mathrm{mg} / \mathrm{kg} / \mathrm{d} .^{17}$ However, recent experience suggests that a preferred dose of $0.2 \mathrm{mg} / \mathrm{kg} / \mathrm{d}$ for two days. ${ }^{2} 48$ Maintenance dose is largely weight dependent but with an independent effect of age, such that younger children require a higher dose per $\mathrm{kg}$ than older children, who in turn require more than adults (for whom an age dependent rather than weight dependent effect has previously been reported ${ }^{9}$ ). These differences are quite striking, particularly in infants less than 1 year old, who required average doses of around $0.32 \mathrm{mg} / \mathrm{kg} / \mathrm{d}$ to maintain an INR of $2-3$ in the Canadian study. ${ }^{4}$ In the Manchester cohort the dose requirements were lower in all age groups but the youngest children (less than 2 years) required maintenance doses around twice that for 11-18 year old children and around three times the doses needed for adults. The difference in dose requirements between the two studies probably reflects a different case mix. The Canadian cohort appears to have been less stable from a clinical point of view and included many very young children who required exceedingly high doses, perhaps due to the presence of vitamin $\mathrm{K}$ supplements in many of the local infant milk formula preparations. Also there was a higher proportion of patients receiving secondary prophylaxis which in adults has been shown to require higher doses of warfarin. ${ }^{9}$

Satisfactory comparison cannot be made with most other studies which have assessed anticoagulant requirements in children. Woods et al documented anticoagulant doses in 31 children with prosthetic valves. ${ }^{10}$ While the older children required larger doses, the correlation with age was poor. These investigators noted increased requirements with sexual development, but did not consider the possible influence of weight. In a smaller study of 20 children (age range 3 months to 9 years) with mechanical valve prostheses, Bradley et al ${ }^{11}$ recorded a mean warfarin dose of 0.16 $\mathrm{mg} / \mathrm{kg} / \mathrm{d}$. However, children under 1 year required a mean warfarin dose of 0.32 $\mathrm{mg} / \mathrm{kg} / \mathrm{d}$. The monitoring of warfarin control was by simple prothrombin time ratio rather than standardised INR. This makes comparison with our results more difficult but it is likely that their cohort, in terms of level of anticoagulation, was most comparable with our high INR group who had a median warfarin requirement similar to the quoted $0 \cdot 124$ $\mathrm{mg} / \mathrm{kg} / \mathrm{d}$.

Initial inspection of our data suggests that the quality of anticoagulant control (as determined by the proportion of the results within target INR range, the interval between visits, and the frequency of dose changes) did not appear ideal. However, children with target INR of $2 \cdot 0-3 \cdot 0$ were on target on $62 \%$ of visits, which compares favourably with $46 \%$ of children reported by Andrew et $a l^{4}$ and $60 \%$ of adults reported by Poller et al. ${ }^{12}$ The inferior performance in the Canadian study ${ }^{4}$ was associated with a more frequent clinic attendance. This may reflect a higher proportion of patients only recently started on anticoagulants as well as a more strict protocol for dosage alteration. Our poor performance in the higher INR group (INR 3.0-4.0), also seen in adult 
anticoagulant patients, ${ }^{12}$ presumably reflects an element of doctor anxiety over high INRs, combined with a willingness to accept as satisfactory an INR in the 2.5-3.0 range. In our cohort such results, unless repeated on consecutive visits, rarely triggered a dose increase or an early return visit. There were no thrombotic sequelae in this group of children despite INR values being below target on $52 \%$ of clinic visits. This supports the view that INRs of $2 \cdot 5-3 \cdot 0$ provide adequate protection in children with prosthetic valves. ${ }^{4}$

Haemorrhagic complications were uncommon and usually minor, but one poor attender suffered a non-fatal subdural haematoma, requiring permanent cessation of oral anticoagulants. Children in the high INR group reported bleeding problems on $4.8 \%$ of clinic visits. This is no more than would be expected in adult patients and is less than the $19 \%$ reported in the Canadian study, where no patient had a target INR above 3.0. ${ }^{4}$

Thus our experience, although small, suggests that oral anticoagulation in children, following adult oriented guidelines, is effective in both primary and secondary prevention of thromboembolism. Haemorrhagic complications occur no more commonly than in adults but may be as severe, particularly at higher INR ranges. A lower INR range of 2.5-3.0 for children with prosthetic valves, as employed by Andrew et $a l^{4}{ }^{4}$ may be more acceptable. A rough guide to likely maintenance dose may be calculated from the child's weight, but careful attention should be given to other influential factors such as age, potentially interfering drugs, and, in the very young, the use of infant formula feeds.

We thank the anticoagulant clinic staff for their help in data collection.

1 Evans DIK, Rowlands M, Poller L. Survey of oral anticoagulant treatment in children. $\mathcal{f}$ Clin Pathol 1992; 45 $707-8$.

2 David $M$, Andrew $M$. Venous thromboembolic complications in children. $\mathcal{F}$ Pediatr 1993; 123: $337-46$

3 Poller L, BCSH Haemostasis and Thrombosis Task Force of the British Society for Haematology. Guidelines on ora anticoagulation: second edition. F Clin Pathol 1990; 43: 177-83.

4 Andrew M, Marzinotto V, Brooker LA, et al. Oral anticoagulation therapy in pediatric patients: a prospective study. ulation therapy in pediatric patien.

5 Hirsh J. Oral anticoagulant drugs. N Engl f Med 1991; 324, 1865-75.

6 Cromme-Dijkhuis AH, Henkens CMA, Bijleveld CMA Hillege HL, Bom VJJ, van der Meer J. Coagulation factor abnormalities as possible thrombotic risk factors after Fontan operations. Lancet 1990; 336: 1087-90.

7 Carpentieri U, Nghiem QX, Harris LC. Clinical experience with an oral anticoagulant in children. Arch Dis Child 1976; 51: 445-8.

8 Doyle JJ, Koren G, Cheng MY, Blanchette VS Anticoagulation with sodium warfarin in children: effect of loading regimen. $\mathcal{F}$ Pediatr 1988; 113: 1095-7.

9 James AH, Britt RP, Raskino CL, Thompson SG. Factors affecting the maintenance dose of warfarin. $f$ Clin Pathol 1992; 45: 704-6.

10 Woods A, Vargas J, Berri G, Kreutzer G, Meschengieser S, Lazzari MA. Antithrombotic therapy in children and adoLazzari MA. Antithrombotic therapy in chil

11 Bradley LM, Midgley FM, Watson DC, Getson PR Scott LP. Anticoagulant therapy in children with mechanical prosthetic cardiac valves. Am $\mathcal{F}$ Cardiol 1985 ; mechanical

12 Poller L, Wright D, Rowlands M. Prospective comparative study of computer programs used for management of warfarin. F Clin Pathol 1993; 46: 299-303. 